American J. of Engineering and Applied Sciences 4 (3): 380-389, 2011

ISSN 1941-7020

(C) 2014 K.P. Kolhe et al., This open access article is distributed under a Creative Commons Attribution

(CC-BY) 3.0 license

\title{
Stability and Ergonomic Design Features of Tractor Mounted Hydraulic Elevator for Coconut Harvesting
}

\author{
${ }^{1}$ Kishor Purushottamrao Kolhe, ${ }^{2}$ Ashok G. Powar, \\ ${ }^{2}$ Amit D. Dhakane and ${ }^{3}$ Sham H. Mankar \\ ${ }^{1}$ Department of Mechanical Engineering, \\ ${ }^{2}$ Department of Farm Machiney and Power, \\ Bahasaheb Sawant Konkan Krishi Vidyapeeth, \\ Dapoli, Dist, Ratnagiri, 415 712, India \\ ${ }^{3}$ Department of Mechanical Engineering, PCCE, University of Pune, India
}

\begin{abstract}
Problem statement: The most important design criterion of mechanized device was safety; safety comprises both the safety of operator and safety of maintenance personnel. Failures and safety of harvesting platform of Tractor Mounted Hydraulic Elevator (TMHE) powered by tractor PTO was tested by finite element method for the mechanical harvesting of coconut orchards using digital ergonomic hart rate meter. The objective of this study was to study the stability of the THME by finite element method, operational safety and power requirement for the use of this elevator for coconut harvesting. Provide sufficient adjustment and space to account for variation in body sizes, ensure controls were situated within suitable reach and were properly marked. Approach: The modal analysis was carried out for the whole assembly of tractor mounted hydraulic elevator by using Ansis software. The digital polar hart rate meter RS400TM having infrared connectivity sensor was used for recording the hart rates. The research stusy was conducted at, Dr. Balasaheb Sawant Kokan Krishi Vidyapeeth Dapoli. The harvesting of coconuts was performed by manual climbing labor and by tractor mounted hydraulic elevator. The technical assessments included the use of biomechanical models, vibration testing equipment, ODR, BPDS. The ergonomical evaluation results of the above study were correlates to decide the feasibility, safety and efficiency of Tractor mounted hydraulic elevator for coconut harvesting. The PTO rpm influence for the lifting and lowering of the harvesting platform was studied experimentally by using digital tachometer. Results: The better stability results with the controlled vibrations and frequency of the lifting platform and welded joints were recorded by keeping constrained boundary conditions. Ergonomically operational safe and controlled heart rates were recorded. Hence the labors can continuously do the coconut harvesting work by using the tractor mounted hydraulic elevator. The minimum PTO power was required for the coconut harvesting by using tractor mounted hydraulic elevator. Conclusion/Recommendation: The tractor mounted hydraulic elevator is suitable, safe, less hazardous and economical as compared to manual climbing for coconut harvesting. Hence it is recommended to use tractor mounted hydraulic elevator for harvesting, cleaning and breeding of coconut orchards upto $14 \mathrm{~m}$ height.
\end{abstract}

Key words: Tractor Mounted Hydraulic Elevator (TMHE), mode shape analysis, fem analysis, heart beat, harvesting platform, mechanical harvesting, coconut orchards, coconut harvesting, ergonomic design, design features

\section{INTRODUCTION}

Human labor is the single costliest input in farming operations contributing to major part of the total cost of various farm operations. Tractor mounted hydraulic elevator hitherto have not been theoretically analyzed and ergonomically developed. Hence there is an urgent need to study the theoretical analysis and ergonomic aspects in detail to quantify the stability and drudgery involved in the TMHE operations. This would greatly help the researchers to appropriaetly design simple and labor effective gadget considering ergonomics requirements. Such designs of tractor mounted hydraulic elevator would not only minimize drudgery

Corresponding Author: Kishor Purushottamrao Kolhe, Department of Mechanical Engineering, Dapoli, Distric, Ratnagiri, 415 712, India Tel: -09422052176 
of the labors but also increase productivity at reduced expenditure levels. A cardinal principal in ergonomics is that since everything is designed for human use, his/her characteristics should be considered from the very beginning of the design cycle. The checklist scores the ergonomic hazards found in the job based on their duration. A total score of 7 or greater indicates that this may be a problem job. Workers who perform the jobs have the best knowledge and perspectives, when it comes to assessing a job for ergonomic hazards. No investigation would be complete without consulting workers about what the root cause of the problem might be and how best to the problem. There are also a number of ergonomic ratings scales that can be used for one or more workers to get an idea about their perceptions of the job. These perceptions can be in the form of perceived discomfort in the job, the level of effort required to do the job and in comparing before and after changes to the job. The Occupational Health Centre has a resource centre that includes resources on how to use these rating scales correctly and how to interpret their findings.

Need for ergonomic evaluation of harvesting machineries: Systematic efforts to evaluate ergonomical the harvesting practice of coconut climbing labors by manual climbing and machine climbing methods. Hence human energy measurements for different operations performed under different environmental conditions are essential. These measurements are also important from the safety point of view because whenever the physical capacity of a person is exceeded, it is bound to cause considerable fatigue and large reduction in the alertness of the person making the operation unsafe. Thus, investigations on ergonomical evaluation of climbing machineries of coconut can provide a rational basis for recommendation of methods and improvement in equipment design for more output and safety. Therefore, to make the tractor mounted hydraulic elevator suitable for the workers, due attention needs to be given to their capabilities and limitations while designing and using different equipment. Keeping in view the above facts, the present study on "Ergonomical evaluation of climbing practices of labor manually and by machine for assessing their suitability for coconut harvesting" was undertaken with the following specific objectives.

- To measure physiological cost of the worker subjects while performing various coconut harvesting operations with selected equipment namely manually operated and tractor mounted hydraulic elevator
- To assess the overall discomfort and body part discomfort rating of the subject in the operation of tractor mounted hydraulic elevator

- To incorporate ergonomic design features in the tractor mounted hydraulic elevator for improving the operational comfort of the workers

Rectangular steel plates are widely used in various steel structures and steel industries. Considering the significance of this matter, lateral vibration of thick rectangular plates was studied on the basis of mindlin plate theory. The plate frequencies were calculated for this boundary condition for a wide range of plate sizes and thicknesses. The plate mode shapes were obtained for different cases and the effect of changes in boundary conditions; size ratio and thickness on the vibration behavior of rectangular steel plates. These results can provide a good gridline for efficient design and prevention of using high safety factors (Sadrnejad et al., 2009). Kolhe and Jadhav tested the performance of tractor mounted hydraulic elevator for mango pruning by conducting the experiments on tractor mounted hydraulic elevator by stability analysis by using digital load cell. The safe vibrations and stability of elevator is noted upto $12 \mathrm{~m}$ height of elevator is $150 \mathrm{~kg}$ load in the harvesting bucket. Figure $2 \mathrm{a}$ and $\mathrm{b}$ presets resourceful use of tractor mounted hydraulic elevator for mango and coconut harvesting (Kolhe and Jadhav, 2011; Kolhe, 2009).

\section{MATERIALS AND METHODS}

The theoretical analysis of the elevator was carried out by using finite element method, using ANSIS 10 and Abqus.6.9 software for finding the minimum displacement of the existing prototype elevator components. The FE MESHING was carried out as shown in Fig. 3. Components of the assembly are meshed with brick elements. Constrained boundary conditions are applied at the tractor representation base. The different models were made for the better safety and design of the elevator in the proposed design. The PTO performance of the tractor was studied by using digital tachometer for the varying tractor accelerating and decelerating tractor speed for 430, $1560 \mathrm{rpm}$ for an efficient and smooth working of the elevator. The tractor model used for this study was $35 \mathrm{hp}$ tractor. While conducting the experiments the PTO rpm was varied from 430, 600, 1000, 1200, 1400 and 1560 respectively. The lifting platform was lifted $7 \mathrm{~m}$ from ground at every PTO rpm, simultaneously the time was noted by using stop watch of $0.02 \mathrm{~s} \mathrm{LC}$. 
Am. J. Engg. \& Applied Sci., 4 (3): 380-389, 2011

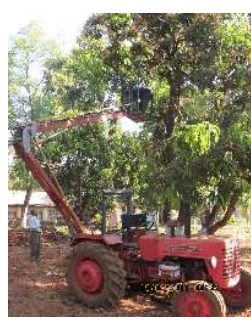

(a)

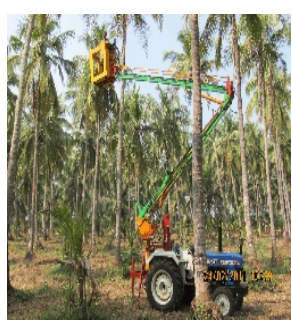

(b)
Fig. 1: (a) Tractor mounted hydraulic elevator using for coconut and mango harvesting (b) Tractor mounted hydraulic elevator using for coconut harvesting

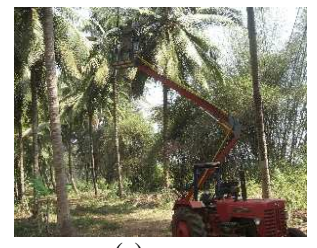

(a)

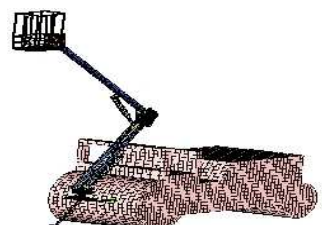

(b)
Fig. 2: FE MESHING of tractor mounted hydraulic elevator

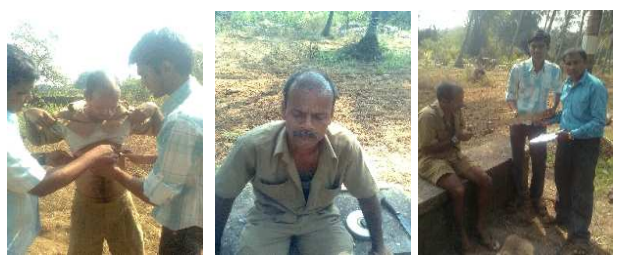

(a)

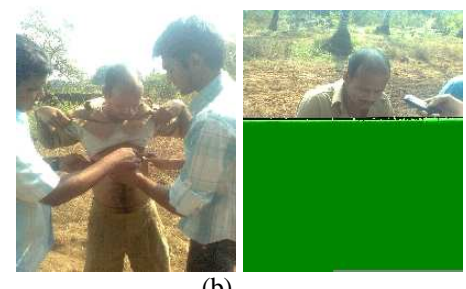

(b)

Fig. 3: (a) Heart rate measurement of manually climbing labour, for coconut harvesting (b) Coconut harvesting by same labor by climbing with TMHE for Coconut harvesting

The ergonomical study of the tractor mounted hydraulic elevator is carried out by using the guidelines and standard of ergonomics by following methodology.

Health and safety committee assessment: The Manitoba labor's ergonomic guideline contains a checklist that can be used to score tasks for ergonomic risks, refer to Appendix A for details. The characteristics of this stooping task scored 7. A score over 7 indicates a hazardous task. The main risk factors are posture and duration of the task.

Technical assessment: Electromyography (EMG) is the study of muscular activity. A tool can be used to measure the muscular activity of muscles and therefore, determine how much effort is being produced and for how long. The readings are compared to the individual's maximum effort. During this task it was found that an average of $28 \%$ of a worker's maximum low back effort was used when stooping and reaching with upper body support. Up to $50 \%$ was used when there was no upper body support. When these muscular activities occurred for more than 15 min then worker discomfort increased significantly.

Worker consultation: A rating scale of worker 's perceived discomfort on the lower back increased from 2,6 as the task duration lasted longer than $15 \mathrm{~min}$. This correlated with the EMG findings of twisting and lack of upper body support.

Standards and guidelines: Scientific literature found many studies linking continuous stooping and high muscular activity with increased reporting of low back injuries.

The EMG results for the low back muscles found that after 5 min of working in an unsupported upper body position, the ratings of discomfort increased. When there was intermittent supporting of the upper body then discomfort did not increase until after 15 min of work. Therefore, it was recommended that work tasks should be changed after $15 \mathrm{~min}$ of stooping in order to reduce low back fatigue (Alexander et al., 2001; Astrand, 2003; Astrand et al., 1965; Corlett and Bishop, 1976; Ayoub and McDaniel, 1974; Eakin, 1992) Manitoba Labor Workplace Safety and Health Division (National Research Council, 2001; Sundstrom, 2000). The ergonomically evaluation of the developed tractor mounted and hydraulic elevator was carried out at coconut research plot, Dr Balasaheb Sawant Konkan Krishi Vidyapeeth, Dapoli, Dis, Ratnagiri (Maharashtra, India). Figure 1 and $2 a$ and $b$ presents the experimental setup of heart rate measurement of the working labour. The hart rate of the working labors were recorded by using Digital polar hart rate measurement meter. The experiments were carried for three different labors for manual climbing method and by using tractor mounted hydraulic elevator for coconut harvesting. 
Am. J. Engg. \& Applied Sci., 4 (3): 380-389, 2011

Table 1: Test results of Ergonomical evaluation of coconut harvesting by manual climbing labor and by tractor mounted coconut climber

\begin{tabular}{|c|c|c|c|c|c|c|}
\hline \multirow[b]{2}{*}{ Particular } & \multicolumn{2}{|l|}{ Operator 1} & \multicolumn{2}{|l|}{ Operator 2} & \multicolumn{2}{|l|}{ Operator 3} \\
\hline & Machine & Manually & Machine & Manually & Machine & Manually \\
\hline Name & Suhas Bhatkar & Suhas Bhatkar & Pramod Bhatkar & Pramod Bhatkar & Vinod Kadam & Vinod Kadam \\
\hline Age (years) & 49 & 49 & 43 & 43 & 24 & 24 weight \\
\hline Weight (Kg) & w & 48 & 48 & 42 & 42 & 4545 \\
\hline Height & $5.5 ”$ & $5.5^{\prime \prime}$ & $5.1 ”$ & $5.1 "$ & $5.8 ”$ & $5.8 ”$ \\
\hline Physical fitness & good & good & good & good & good & good \\
\hline Tree height (Foot) & 45 & 45 & 45 & 45 & 44 & 44 \\
\hline Tree variety & Banavali & Banavali & Banavali & Banavali & Banavali & Banavali \\
\hline $\begin{array}{l}\text { Number of tree } \\
\text { cover in } 20 \mathrm{~min}\end{array}$ & 4 & 2 & 3 & 2 & 3 & 1 \\
\hline $\begin{array}{l}\text { Body Part Discomfort } \\
\text { Score, (BPDS) }\end{array}$ & 18.32 & 33.25 & 18.33 & 47.25 & 26 & 49.5 \\
\hline $\begin{array}{l}\text { Overall Discomfort } \\
\text { Rate, (ODR) }\end{array}$ & 2 & 8 & 3 & 7 & 5 & 9 \\
\hline
\end{tabular}

Table 2: Test results of tractor mounted hydraulic elevator Time required to lift the bucket up to $5 \mathrm{~m}$ height from ground (sec)

\begin{tabular}{|c|c|c|c|c|c|c|c|c|}
\hline PTO rpm & $\mathrm{R} 1$ & $\mathrm{R} 2$ & $\mathrm{R} 3$ & Mean & $\mathrm{R} 1$ & $\mathrm{R} 2$ & R3 & Mean \\
\hline 430 & 17.0 & 14.0 & 13.2 & 14.730 & 6.0 & 6.0 & 6.0 & 6.00 \\
\hline 600 & 10.2 & 12.0 & 11.4 & 11.200 & 6.2 & 5.4 & 7.2 & 6.27 \\
\hline 800 & 8.4 & 8.0 & 8.0 & 8.133 & 6.0 & 6.5 & 5.6 & 6.03 \\
\hline 1000 & 9.0 & 8.5 & 9.0 & 8.833 & 6.0 & 6.0 & 6.0 & 6.00 \\
\hline 1200 & 10.0 & 10.0 & 10.0 & 10.000 & 6.0 & 6.0 & 5.4 & 5.80 \\
\hline 1400 & 12.0 & 13.5 & 14.2 & 13.230 & 5.7 & 6.0 & 6.0 & 5.90 \\
\hline 1560 & 16.8 & 17.0 & 18.0 & 17.270 & 5.8 & 6.0 & 5.4 & 5.73 \\
\hline
\end{tabular}

The labors work in continuation of one and half hours was taken for the above study for getting the accurate readings the same group of workers were used for manual and machine coconut harvesting. The working hart rates by both the methods were compared for deciding the feasibility, operational safety and efficiency of the machine for coconut harvesting. The ergonomical evaluation of coconut climbing labors is carried out as follows.

\section{RESULTS}

The physiological observations, BPDS and ODR of the labors used for coconut harvesting in this study are are presented in Table 1.

Effect of PTO rpm on the lifting and lowering time of the TMHE: The response of TMHE to varying PTO rpm is presented at Table 2. In this study the lowest and highest rpm of the tractor PTO is measured by using tachometer. It is observed that the lowest rpm at minimum throttle is 430 . The highest rpm at full throttle is 1560 .

It is observed from Table 1 that as the tractor PTO rpm increases the response time to lift the bucket decreases, the lowest time $8.133 \mathrm{sec}$ required to lift the bucket is $800 \mathrm{rpm}$. The highest time $17.27 \mathrm{sec}$ at 1560 rpm. Hence PTO rpm influences the response time of the TMHE for lifting the bucket. The lowering of platform takes the time in the range of 5.73, $6.27 \mathrm{sec}$. The lowest time observed at $1560 \mathrm{rpm}$ while highest time required at $600 \mathrm{rpm}$ for lowering the platform.

\section{DISCUSSION}

Figure 4a-n presents the experimental results of FEM analysis of Tractor Mounted Hydraulic Elevator in different modes. In the above figures the maximum mode shapes were observed at the lifting platform or the region between the upper arm and the lifting platform of the elevator shown by various color regions in the above figure. The frequency in all the cases was very less at the lifting platform and the remaining parts of the elevator. The maximum displacement was noted on the area of mode shape. The weak areas were identified in the existing design of this elevator. The above failures are due to improper material selection, improper welding methods or weak pin joints. However, very low frequencies are noted from this mode shape analysis which is need to be improvement in the proposed design of the elevator. The minimum vibrations are needed for the maximum stability of the machine. 
Am. J. Engg. \& Applied Sci., 4 (3): 380-389, 2011
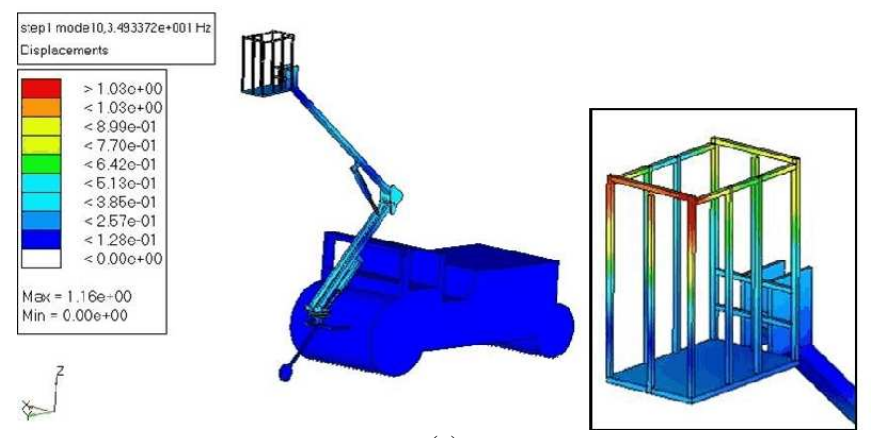

(a)

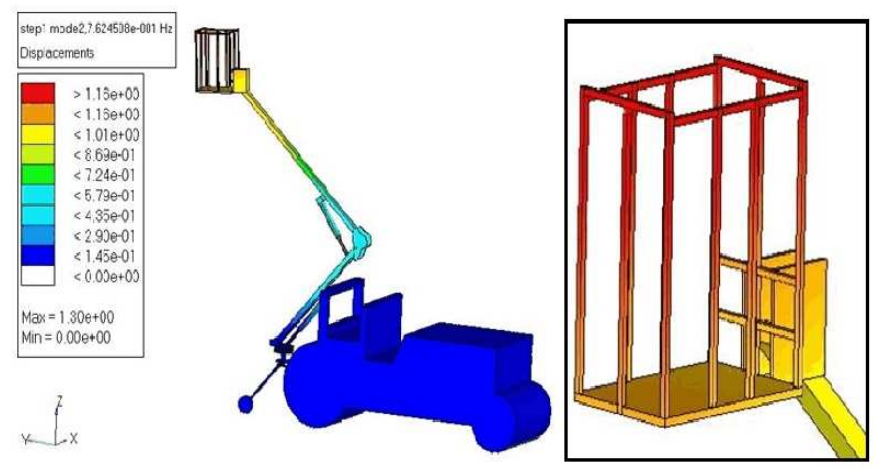

(b)

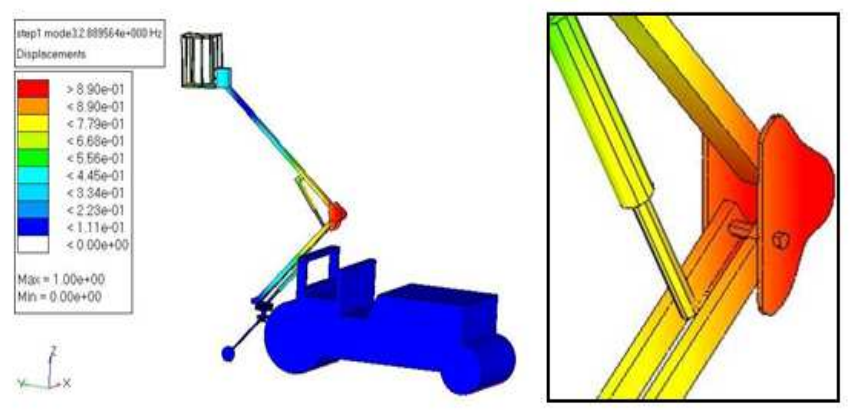

(c)

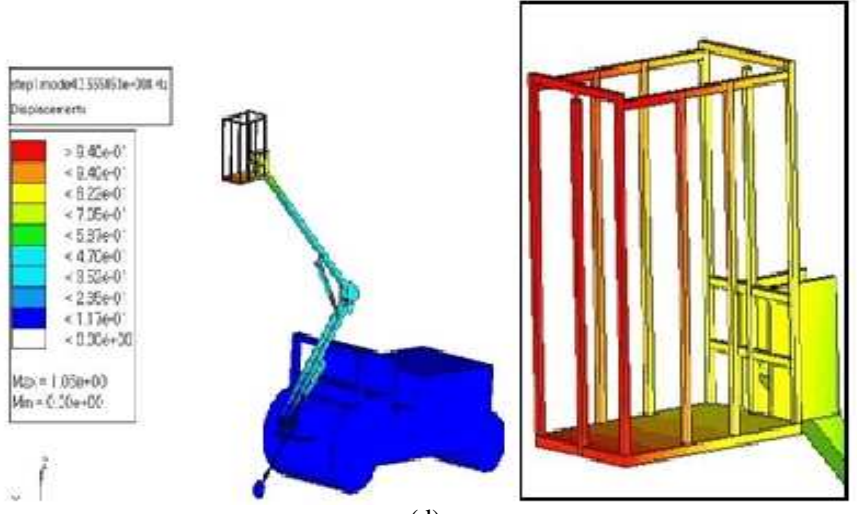

(d) 
Am. J. Engg. \& Applied Sci., 4 (3): 380-389, 2011
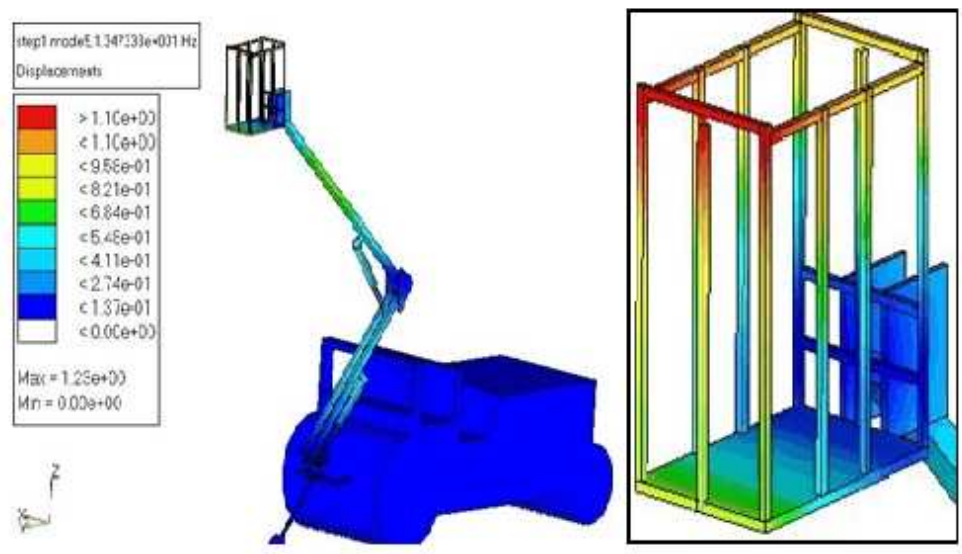

(e)
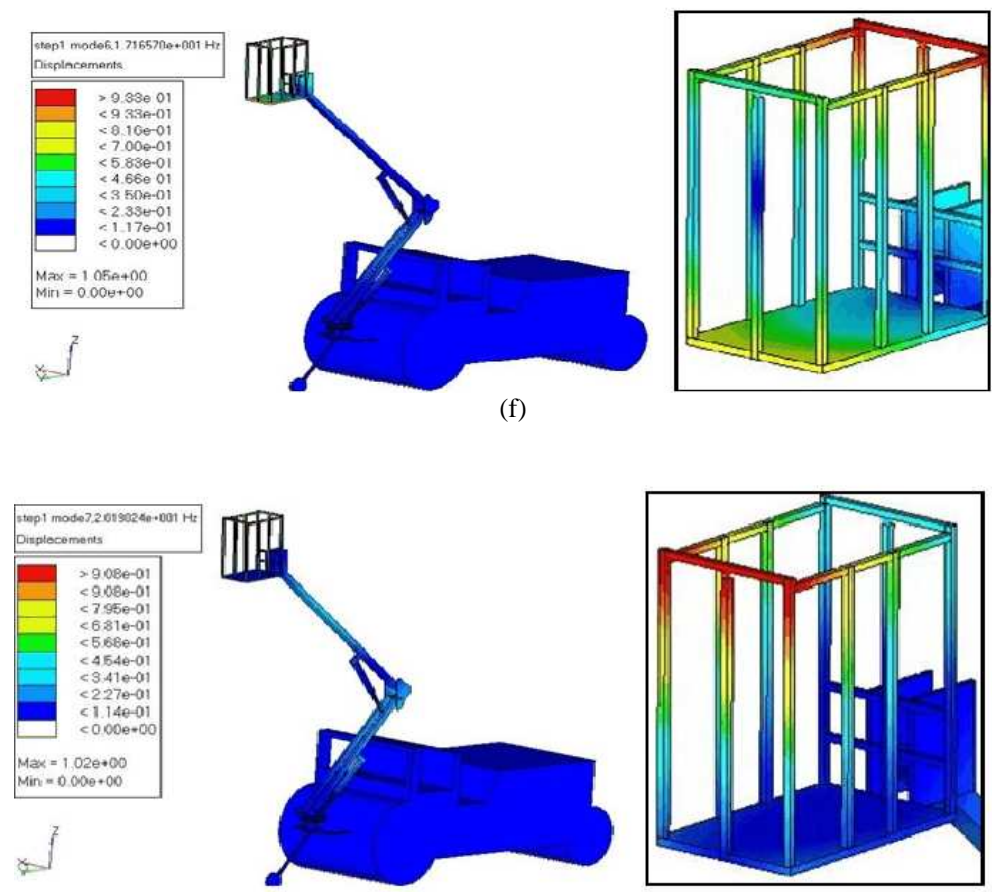

(g)
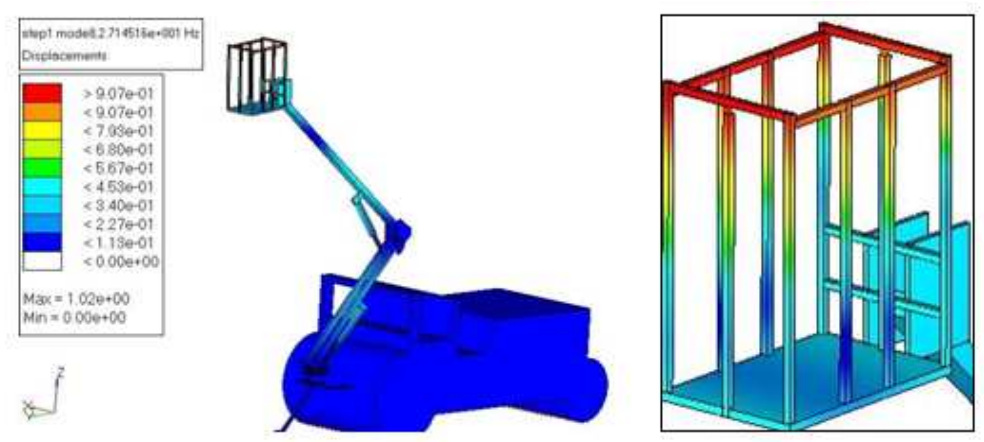
Am. J. Engg. \& Applied Sci., 4 (3): 380-389, 2011
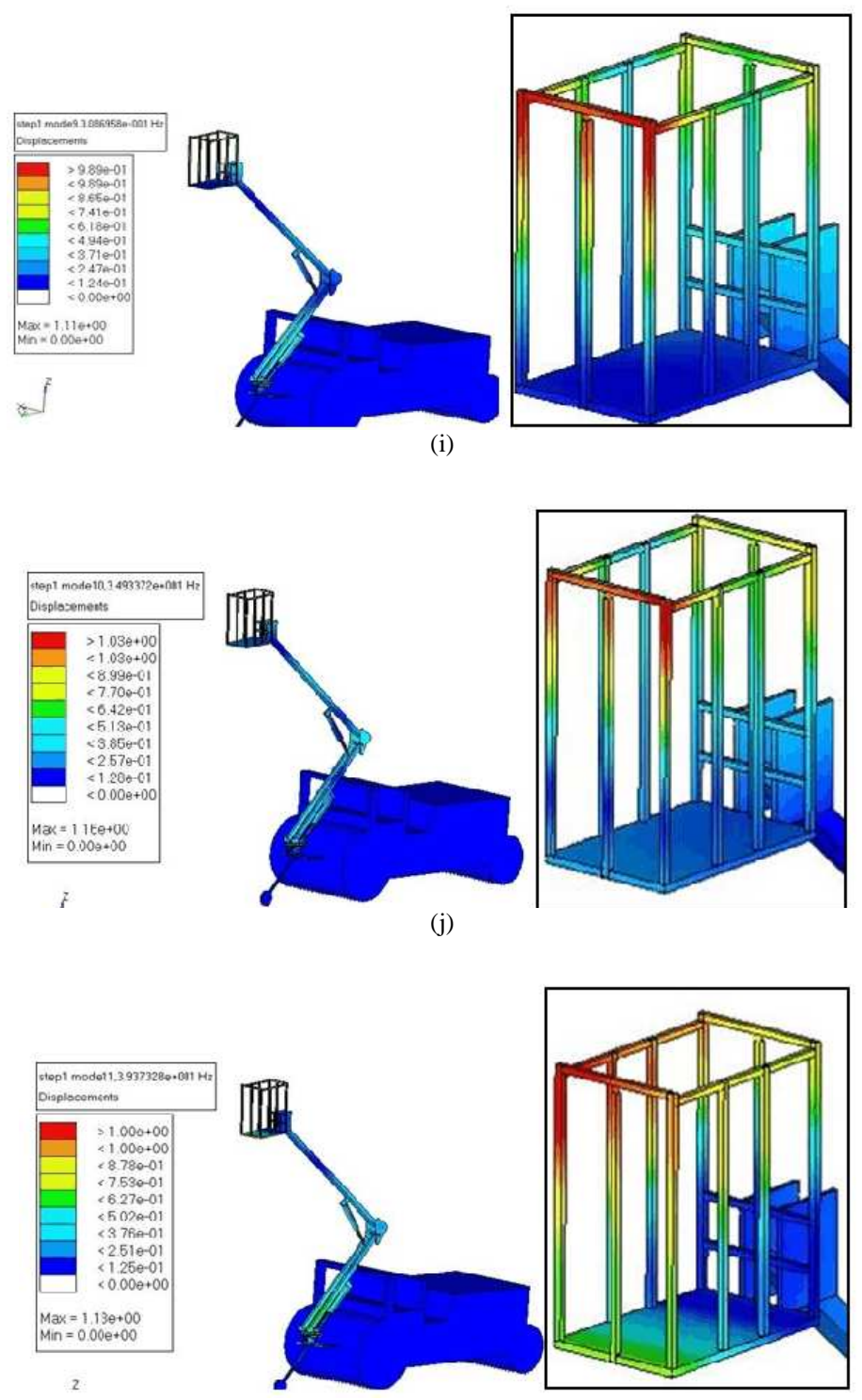

(k)
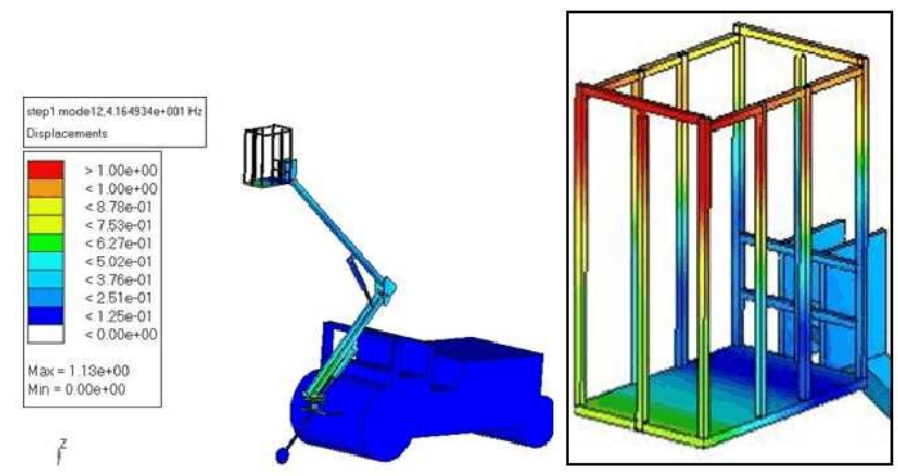
Am. J. Engg. \& Applied Sci., 4 (3): 380-389, 2011
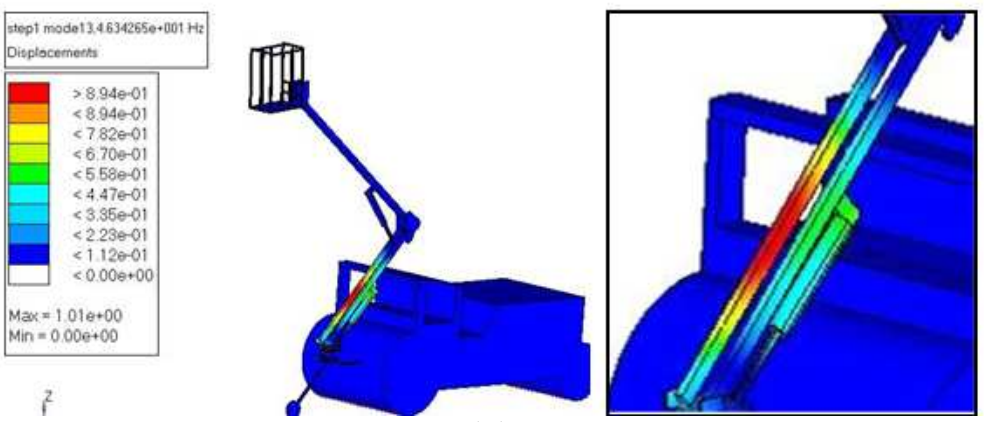

(m)
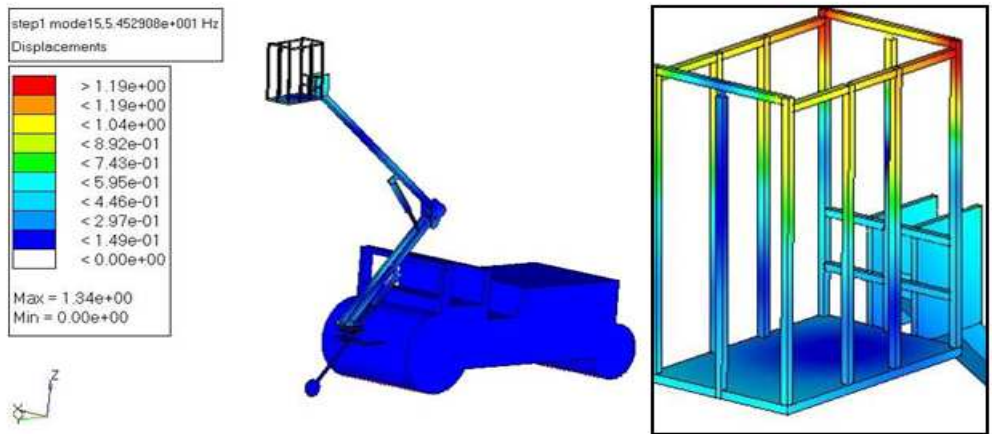

(n)

Fig. 3: FEM analysis of tractor mounted hydraulic elevator

Nevertheless, all the above factors are based on the fact of better strength of the vicinity, e.g., welded joint, pin joint joints and accessories of the machine elements. The metal joining techniques, material selection will improve the proposed design of the elevator.

In ideal condition for getting the good stability, the displacement of the machine element in static position should be zero in various modes. But practically it is observed that the there are always some displacement in the machine due to eternally applied factors on the machine under impact force like wind energy and other atmospheric conditions. Figure 4. presents the FEM analysis of Tractor Mounted Hydraulic Elevator for however it is observed that practically there is certain displacement in the machine element in static condition, hence here our endeavor is to get the minimum value of displacement in the machine elements in the various modes of the machine, for getting better stability and minimum vibrations in the machine element. However, from the study of existing prototype elevator the theoretical study was done for getting the better safety and stability of the proposed design of the elevator by doing the certain modifications in the harvesting platform, harvesting arm, supporting wheel arm supporting beam of the existing prototype elevator.
From the BPDS results the average BPDS for the climbing labors by both the methods is noted. The BPDS obtained for TMHE is below 40, hence the operator can be comfortably works for eight hours without fatigue. Whereas by manual climbing operation the BPDS score is above 40, which indicates that the manual climbing labor is tired labor. Thus these labors will require rest during harvesting of coconuts. Hence the manual climbing labors filled discomfort during the coconut harvesting operation. Due to which the worker cannot work continuously eight hours.

Hence the developed machine is ergonomically best suited for coconut harvesting operation.

Overall discomfort rate score calculated for the Health and Safety Committee Assessment by using manual climbing method is above 7 . Hence the manual task of coconut climbing is hazardous task. A score over 7 indicates a hazardous task. The main risk factors are posture and duration of the task. Nevertheless, the score obtained by using tractor mounted and self propelled coconut climber is below 7. Hence the machine is safe for the Health and Safety Committee Assessment. Hence the machine developed for harvesting of coconuts is recommended for coconut harvesting upto $14 \mathrm{~m}$ tree height. 
Am. J. Engg. \& Applied Sci., 4 (3): 380-389, 2011

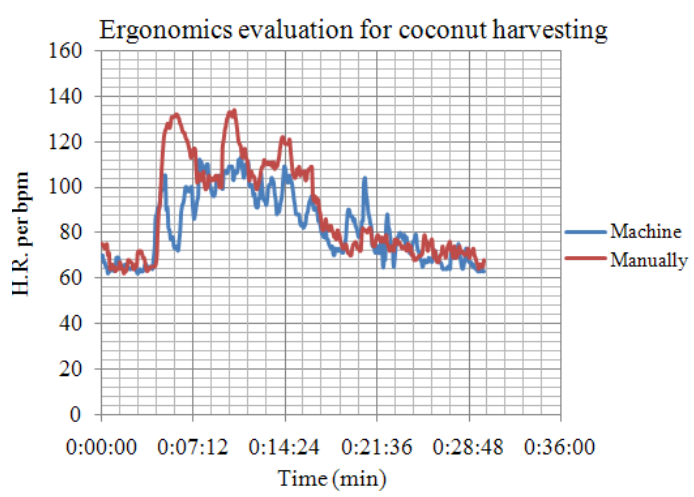

Fig. 5: Comparative study of heart beat measurement by manual climbing and by using TMHE by $\mathrm{X}$ - labor

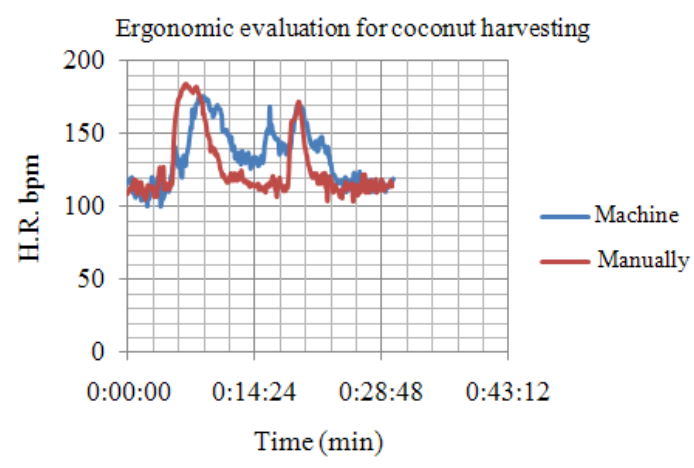

Fig. 6: Comparative study of heart beat measurement by manual climbing and by using TMHE by Y- labor

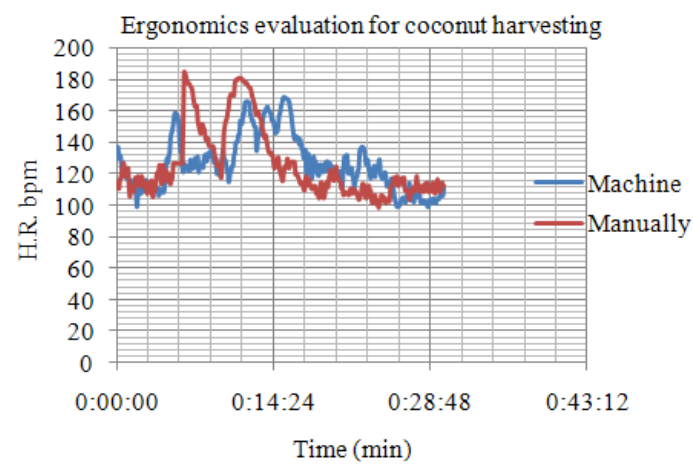

Fig. 7: Comparative study of heart beat measurement by manual climbing and by usingTMHE by Z-labur

Figure 5-7 presents the test results of various labors by using digital hart rate meter. From Fig. 5, It is observed that the non significant variations are noted for manual climbing operation by the labor for coconut harvesting. Nevertheless, the significant variations in the heart beats are noted by the tractor mounted and self propelled coconut climber for coconut harvesting. Thus the machine tested for coconut harvesting is appropriate method, the heart rate noted are comfortable and not in dangerous. But the results obtained by manual climbing are not in the specified range. For manual climbing Electromyography (EMG) is the study of muscular activity of climbing labor. A tool can be used to measure the muscular activity of muscles and therefore, determine how much effort is being produced and for how long. The readings are compared to the individual's maximum effort. During this task it was found that an average of $28 \%$ of a worker's maximum low back effort was used when stooping and reaching with upper body support. Up to $50 \%$ was used when there was no upper body support. When these muscular activities occurred for more than 15 min then worker discomfort increased significantly.

\section{CONCLUSION}

From this study following conclusions were made:

- From the theoretical analysis the weak vicinity observed in the elevator assembly are at the joint region of the elevator, like welded joints and pinjoints of lifting platform, harvesting arm and turn table respectively. Hence for avoiding the future failures the recommended joining techniques and material will be required

- The safety and less hazardous results are noted for the tractor mounted hydraulic elevator as compared to manual climbing for coconut harvesting

- The tractor PTO has influence on the response time for the lifting of the bucket, but not on lowering the bucket

\section{ACKNOWLEDGEMENT}

The researchers would like to graciously thank to the Coconut Development Board Kochi, Ministry of Agriculture, Government of India, for funding of this research. The researchers also thankful to Hon Vice Chancellor, Dr Balasaheb Sawant Konkan Krishi Vidyapeeth, Dapoli, Dist, Ratnagiri (India) for availing the university research facility for conducting the research experiments of this study.

\section{REFERENCES}

Alexander, D.C., C. Pierpaoli, P.J. Basser and J.C. Gee, 2001. Spatial transformations of diffusion tensor magnetic resonance images. IEEE Trans. Med. Imag., 20: 1131-1139. DOI: $10.1109 / 42.963816$ 
Astrand, P.O., B. Ekblon, R. Messin, B. Stallin and J. Stenberg, 1965. Intra-arterial blood pressure during exercise with different muscle groups. J. Applied Physiol., 20: 253-256.

Astrand, P.O., 2003. Textbook of work physiology Physiological Bases of Exercise. 4th Edn., Human Kinetics, Champaign, IL., ISBN: 0736001409, pp: 649.

Ayoub, M.M. and J.W. McDaniel, 1974. Effects of operator stance on pushing and pulling tasks. AIIE Trans., 6: 185-195. DOI: 10.1080/05695557408974953

Corlett, E.N. and R.P. Bishop, 1976. A technique for assessing postural discomfort. Ergonomics, 19: 175182. PMID: 1278144

Eakin, J.M., 1992. Leaving it up to the workers: Sociological perspective on the management of health and safety in small workplaces. Int. J. Health Serv., 22: 689-704. PMID: 1399176

Kolhe, K.P. and B.B. Jadhav, 2011. Testing and performance evaluation of tractor mounted hydraulic elevator for mango orchard. Am. J. Eng. Applied Sci., 4: 179-186. DOI: 10.3844/ajeassp.2011.179.186
Kolhe, K.P., 2009. Design and development of tractor mounted hydraulic lifter for harvesting spraying and pruning of horticultural fruit trees. Int. J. Agric. Eng., 2: 170-175.

National Research Council, 2001. Musculoskeletal Disorders and the Workplace: Low Back and Upper Extremities. 1st Edn., National Academies Press, Washington, DC., ISBN: 0309072840, pp: 492.

Sadrnejad, S.A., A.S. Daryan and M. Ziaei, 2009. Vibration equations of thick rectangular plates using mindlin plate theory. J. Comput. Sci., 5: 838842. DOI: 10.3844 jessp.2009.838.842

Sundstrom, L., 2000. Better work environment for small companies in Sweden. Proce. Human Factors Ergon. Soc. Ann. Meet., 44: 175-177. DOI: $10.1177 / 154193120004403326$ 